\title{
Risk-based efficiency assessment of information systems
}

\author{
Eugeni A. Isaev ${ }^{\mathrm{a}}$
}

E-mail: is@itaec.ru

Dmitry V. Pervukhin ${ }^{\mathrm{b}}$

E-mail: dvperv@gmail.com

Georgy O. Rytikov ${ }^{\mathrm{b}, \mathrm{c}}$

E-mail: GR-yandex@yandex.ru

\section{Ekaterina K. Filyugina ${ }^{d}$}

E-mail: ekaterina.filyugina@mail.ru

\section{Diana A. Hayrapetyan ${ }^{e}$}

E-mail: hayrapetyandiana@gmail.com

\footnotetext{
a Institute of Mathematical Problems of Biology, Russian Academy of Sciences (Branch of the Keldysh Institute of Applied Mathematics, Russian Academy of Sciences)

Address: 1, Professor Vitkevich Street, Pushino, Moscow Region 142290, Russia

${ }^{\mathrm{b}}$ State University of Management

Address: 99, Ryazansky Prospect, Moscow 109542, Russia

${ }^{\mathrm{c}}$ Moscow Polytechnic University

Address: 38, Bolshaya Semyonovskaya Street, Moscow 107023, Russia

d Impact Electronics Ltd.

Address: 14/19 build. 8, Novoslobodskaya Street, Moscow 127055, Russia

e Epokha Vozrozdeniya Ltd.

Address: 13 build. 2, Rusakovskaya Street, Moscow 107078, Russia
}

\section{Abstract}

The implementation of information systems is aimed at improving the financial performance of a company, creating a transparent reporting system and improving many other competitive factors. However, the acquisition of these benefits does not negate the complexity of making a decision 
whether or not to implement a particular IT project. The total cost of ownership of the information system throughout the life cycle is usually not considered in comparison with the expected benefits from the use of the system, due to the uncertainty of such benefits. Comparative certainty of approaches and methods is present only in terms of costs, both for a priori (planned) and a posteriori (actual) assessment. It is possible to determine both capital and operating costs accurately enough. Indirect definition of the positive influence of an information system on the activity of the organization also seems possible. However, there are currently no generally recognized methods for analyzing the expected positive effect of an IT project. At the same time, large companies, in accordance with the requirements of the respective regulators and / or due to internal management considerations, build a risk management system to determine the level of capabilities, losses and to prevent adverse events. This study considers the feasibility of an approach to analyze the effectiveness of the implementation of the information system on the basis of the company's risk reduction, leading to a decrease in economic benefits. It takes into account the internal risks of the information system that occur during the installation of the system, its operation and the termination of work with the system.

Key words: risk assessment; IT project management; information system; implementation of information systems.

Citation: Isaev E.A., Pervukhin D.V., Rytikov G.O., Filyugina E.K., Hayrapetyan D.A. (2021) Risk-based efficiency assessment of information systems. Business Informatics, vol. 15, no 1, pp. 19-29.

DOI: 10.17323/2587-814X.2021.1.19.29

\section{Introduction}

$\mathrm{M}$ odern business conditions imply a regime of fierce competition and increasingly shrinking time for decision-making, which is emphasized in many scientific papers [1]. A large number of empirical studies have been conducted confirming the influence of factors such as organizational architecture, production infrastructure and related business processes on the ability of an enterprise to survive and function effectively [2]. At the same time, one of the key aspects of successful company management is the use of information technology and modern software tools, as well as appropriate methods and models (e.g., convolutional neural networks, significantly accelerating the processing of large data sets [3]).
In continuation of the authors' works in the field of evaluating the effectiveness of implementation of IT projects [4], it is worth mentioning the modern hierarchical system of existing classes of information systems (IS). In terms of enterprise architecture, when classifying IS "top-down", first we should mention the group of systems designed to provide operational analytics (examples include SAP HANA, Lumira, Predictive Analytics). This block is followed by ERP-systems that automate individual business processes and support financial and economic management. Operational translation of market needs into specific production tasks is provided by a block of MES, PLM and SCADA systems, where the first is responsible for production in general, the second for product lifecycle management, and the third for the quality of individual production iterations. 
The implementation of each of these systems involves the planning and implementation of an investment project [5]. The ability to assess the feasibility of a project and its relevance becomes a critical task for a company $[6,7]$. At the same time, the introduction of information technology, along with certain expectations, is associated with certain risks ${ }^{1}$ [8]. The positive consequences of the introduction of IS include a well-ordered organizational structure with transparent and uniform reporting, acceleration of the process of analyzing the company's activity with further adoption of strategically important managerial decisions, and automation of many business processes. The negative effect on the key indicators of the company is caused by the cost of the implementation of the IS and the necessary structural reorganization [9], support of the system during its operation, as well as relevant updates of the software product.

To date, the assessment of the effectiveness of the implementation of the IS is still an issue. Along with well-known approaches such as IE (Information Economics), TEI (Total Economic Impact), REJ (Rapid Economic Justification) and BSC (Balanced Scorecard), the standard numerical indicators ROI (return of investment), NPV (net present value), IRR (internal rate of return), EVA (economic value added), ROV (real options valuations) are used to consider projects. The right choice of IT project management methodology is also necessary [10]. As for this paper, it offers an approach to analyze the effectiveness of the implemented information system based on an assessment of the company's risks before and after the implementation of the IT project. An important feature is that it takes into account the internal risks associated with the information system itself and the likelihood of critical failures in its operation [11].

\section{Impact of informational systems on company risks}

The risk management system of large companies provides for the formation of a risk map that can be used, among other things, to determine the positive effect of the introduction of information systems [12]. When determining the impact of risks on the company's performance indicators, attention is paid both to the strength of the negative impact of an individual event on certain indicators and the frequency of certain adverse events occurring.

The influence of risks on company indicators can be estimated in a context of two situations - "as is", i.e. before realization of certain measures directed at reducing risks (for example, before introduction of information system), and "as will be", i.e. after realization of corresponding measures. Thus, the effect of the implementation of the measure (implementation of the IS) can be expressed in the form of the difference of values of the same indicators in the situations "as is" and "as will be".

There are many examples that support a positive conclusion that information systems can reduce a company's risks. In particular, one of the most noticeable factors affecting the key indicators of the company is the adoption of balanced and reasonable decisions, including those made at the senior management level [13]. It is management mistakes that can lead to the disruption of existing business processes. Possible sources of economically unjustified manage-

\footnotetext{
1 The terms "risk" and "risk management" are used hereinafter within the terminology established in the field of risk management and defined, for example, in standards such as ISO 31000, FERMA, Basel, etc.
} 
ment decisions may be both incorrect data, on the basis of which the decision is made, and human factor [14]. The implemented system allows you to significantly improve the methods of collecting and analyzing data, and reduce (up to complete elimination) their manual processing by employees of the company. The results of the analysis of information using algorithms inherent in the IS, provide impartiality and credibility in the formation of reporting, which increases the reliability of the indicators on the basis of which decisions will be taken.

The success stories of companies that have coped with the problem of illiquid goods (or significantly reduced it) by changing the structure of production and the subsequent reduction of warehouse space [4] show the effectiveness of implemented information technology, using the method described in this paper. The risks that can arise from errors in inventory management are mitigated because the need to purchase a substantial number of materials is reduced. At the same time, the need for rapid interaction within the company and with its contractors increases. Getting data in real time becomes a critical factor, which is enabled by information systems.

Another critical factor that has the potential for a negative outcome is the technological side of production. IT solutions provide an opportunity to fix the chain of manufacturing operations within the company [4]. At the same time there is tracking and standardization of activities on interaction with contractors. This allows for the automatic generation of signals on the management of production facilities.

Such examples are given in order to expand the functionality of companies' risk management systems. Consideration of problematic issues, the solution of which is associated with the implementation of the IS, can be assessed on the basis of changes in key indicators as a result of the introduction of a particular information system. This approach covers the issue of assessing the effectiveness of the IT project. However, at the same time a new problem arises: the fact that the risks are not only outside the information system, their source may be the project itself. Thus, to improve the assessment of the project, it is necessary to adjust for the risks arising, for example, in cases of problems during the implementation of the IS, or critical failures during the use of the system, as well as during its decommissioning [15].

\section{Internal risks of information systems}

According to the available research on ERP-systems efficiency, $51 \%$ of implementation projects experience some unforeseen difficulties in the process of IS installation, $53 \%$ of projects demonstrate significant financial difficulties, which exceed the initially approved budget [16], $83 \%$ of projects fail to meet the deadline, $42 \%$ of projects fail to complete the expected characteristics of the implemented technical solution [17, 18 ], $40 \%$ of projects fail to solve the business task after completion and putting the IS into operation [19, 20]. These statistics indicate that managers and investors recognize the presence of significant risks in the implementation of IS. Typically, implementation projects (as well as subsequent system support) are outsourced to external consultants, but this business model raises issues related to conflicts of interest [21] and blurring responsibility for results, which aggravates the potential overall negative effect of project risks [22].

To reduce risk exposure associated with software, system implementation, use, and decommissioning, a number of approaches have been developed to identify problem- 
atic aspects [23]. Some of these approaches are accounted for in ALM-class information systems (e.g., SAP Cloud ALM, Solution Manager), which computerize the lifecycle management process. In general, the risks of IT projects are technical in nature and related to the formulation of requirements, their variability and the speed of updates. At the same time, the most important are the technical aspects, without the implementation of which it is not possible to make the implementation of an information system [24]. Although a group of risks, the identification of which affects the business processes of the company, should be highlighted. The integration of IS with production is often accompanied by a sharp drop in labor efficiency $[25,26]$. Thus, the development of proper strategies and measures to solve this problem is required [27].

Identification of IT project risks is an important effort, which has been carried out by ISACA. The result of this activity has become a document COBIT5 [28], which categorizes the risks in practice into $111 \mathrm{cat}-$ egories. Examples include information leakage risks [29], as well as risks associated with the project life cycle, IS architecture, company infrastructure, software vendor selection, as well as the personnel and their competencies.

The description of risks implies their division into areas of influence. The first type is considered strategic, describing missed opportunities to use information technology to improve the company's efficiency [30]. The second type is directly related to the technical implementation of the IT project. The last type is operational, which corresponds to the operation of the system and the technical support services. These risks, as a matter of fact, are divided by the degree of impact on the company's activities in case of their implementation.
Thus, the assessment of risks in the "as it will be" situation, i.e. after the implementation of the system, should include the internal risks of the information system directly related to its implementation and use.

\section{Evaluation of information systems' impact on company risks and performance indicators}

Using the example of process management, let's consider the issues of evaluating the impact of information systems on the company's risks (and, accordingly, on its key performance indicators), taking into account the internal risks associated with the information systems themselves.

Let's consider a process consisting of several consecutive stages, along the implementation of which there is an increase of some selected performance indicator. If the performance indicator $s$ is the only one, then its values at different stages of the process can be represented as a vector $\overline{\mathbf{s}}=\left\{s_{i}\right\}, i=\overline{0, N}$, where $N$ is the number of process stages. At the same time, $s_{0}$ represents the initial value of the index (i.e., occurring before the beginning of the first stage), $s_{i}$ is the value of the indicator after the completion of the $i$-th stage of the process. Respectively, $s_{N}$ is the value of the indicator after the last, $\mathrm{N}$-th stage of the process, i.e. after completion of the whole process.

Now let's introduce the concept of the coefficient of dynamics, which characterizes the positive dynamics of the efficiency indicator under consideration as certain stages of the process are implemented. For an arbitrary $i$-th stage of the process the value of the coefficient of dynamics is determined as: $k_{i}=s_{i} / s_{i-1}$, where $s_{i}$ is the value of the performance indicator after the completion of the $i$-th stage of the process, and $s_{i-1}$ is the value of the same indicator before the beginning 
of the stage (i.e. after the completion of the preceding stage). In fact, the coefficient of dynamics characterizes the ratio of "input" and "output" of the process. Given the fact that the process consists of several stages, the values of the coefficient of dynamics is a vector $\overline{\mathbf{k}}=\left\{k_{i}\right\}, i=\overline{1, N}$, where $k_{i}$ is the value of the coefficient at the $i$-th stage of the process, $N$ is the number of stages of the process. Since the considered coefficient of dynamics does not take into account either risks or the influence of the information system, we will call it the basic or risk-free one.

The correlation between the initial value of the performance indicator (before the start of the process) and its final value (after the full completion of the entire process) is also easy to derive:

$$
s_{N}=s_{0} \cdot \prod_{i=1}^{N} k_{i},
$$

where $s_{0}$ and $s_{N}$ are the initial and final values of the performance indicator, respectively;

$k_{i}$ is the value of the basic coefficient of dynamics at the $i$-th stage of the process;

$N$ is the number of stages in the process.

Now, let's make an assumption about process-related general risks (information systems, their impact on the process and their internal risks are not considered yet).

Let's define $i$-th stage risk realization probability $p_{i}$ as the probability that this stage of the process will not be executed and, consequently, the expected results will not be achieved. In this case, the probability that the result of the $i$-th stage will be obtained as $\left(1-p_{i}\right)$. For example, if the proportion of manufacturing defects in the performance of the $i$-th technological operation for all possible reasons is $1.3 \%$, then $p_{i}=0.013$, and the probability of successful performance of this operation will be $\left(1-p_{i}\right)=$ 0.987 .
This allows us to determine the variation of the coefficient of dynamics considered above, by adjusting its values taking into account the risks (we will call this variation the coefficient of dynamics of the first kind). Its connection with the basic (risk-free) coefficient of dynamics is as:

$$
k_{i}^{(1)}=k_{i} \cdot\left(1-p_{i}\right),
$$

where $k_{i}$ is the value of the basic (risk-free) coefficient of dynamics at the $i$-th stage of the process;

$k_{i}$ is the value of the coefficient of dynamics of the first kind at the $i$-th stage of the process;

$p_{i}$ is the probability of risk realization at the $i$-th stage of the process.

Note that the coefficient of dynamics of the first kind, corresponding to certain stages of the process, is always lower than the values of the base (risk-free) coefficient, relating to the same stages.

Since the implementation of the information system should help to reduce the probability of internal risk realization, we will introduce such an indicator as the influence of the information system on risks. The value of this indicator, relating to the $i$-th stage of the process $\left(r_{i}\right)$, is in the range $[0,1]$ and indicates that after the implementation of the information system, the probability of risk realization at the $\mathrm{i}$-th stage will decrease and will be equal to $p_{i} \cdot\left(1-r_{i}\right)$. In particular, if $r_{i}=1$, then the implementation of the information system should completely eliminate the risk of failure of the $i$-th stage of the process, and if $r_{i}=0$, then it means that the system has no effect on the risk of this stage.

Hence, another variation of the coefficient of dynamics can be introduced, taking into account the influence of the information system on risks (the coefficient of dynamics of the second kind). Its connection with 
the basic (risk-free) coefficient of dynamics is as:

$$
k_{i}^{(2)}=k_{i} \cdot\left(1-p_{i} \cdot\left(1-r_{i}\right)\right),
$$

where $k_{i}$ is the value of the basic (risk-free) dynamics coefficient at the $i$-th stage of the process;

$k_{i}^{(2)}$ is the value of the coefficient of dynamics of the second kind at the $i$-th stage of the process;

$p_{i}$ is the probability of risk realization at the $i$-th stage of the process;

$r_{i}$ is the impact of the information system on the $i$-th stage risks of the process.

Finally, let us take into account that the information system itself may fail in its operation. These risks are internal to the system. Their presence means that the real impact of the information system on the $i$-th stage risk of the process may be less than the value of indicator $r_{i}$. If we define the probability of internal risk of the information system at the $i$-th stage as $q_{i}$, then the impact of the system on the risk of this stage will be $r_{i} \cdot\left(1-q_{i}\right)$. It is clear that with zero probability of internal system risk its impact on stage risk will not change, but non-zero values of this parameter will lead to a reduction of this impact, up to zero.

Thus, another variation of the coefficient of dynamics (the coefficient of dynamics of the third kind) will take into account all the considered parameters, including the probabilities of internal risks of the information system. The connection of the coefficient of dynamics of the third kind with the basic (risk-free) coefficient is as:

$$
k_{i}^{(3)}=k_{i} \cdot\left(1-p_{i} \cdot\left(1-r_{i} \cdot\left(1-q_{i}\right)\right)\right),
$$

where $k_{i}$ is the value of the basic (risk-free) dynamics coefficient at the $i$-th stage of the process; $k_{i}^{(3)}$ is the value of the coefficient of dynamics of the third kind at the $i$-th stage of the process;

$p_{i}$ is the probability of risk realization at the $i$-th stage of the process;

$r_{i}$ is the impact of the information system on the $i$-th stage risks of the process;

$q_{i}$ is the probability of realization of internal information system risk at the $i$-th stage of the process.

Thus, the assessment of the information system efficiency aimed at reducing the risk of the $i$-th stage of the project can be expressed either as the difference between the values of the coefficients of dynamics of the third kind (after the introduction of the information system, taking into account its impact on the risk of the stage and internal risks of the system itself) and the first kind (before the introduction of the information system), or as the ratio of these values.

The following formulas can be used to estimate the result of the implementation of an ideal (containing no internal risks) and real (with internal risks) information system:

$$
\begin{aligned}
& \Delta s^{\text {ideal }}=s_{0} \cdot\left(\prod_{i=1}^{N} k_{i}^{(2)}-\prod_{i=1}^{N} k_{i}^{(1)}\right), \\
& \Delta s^{\text {real }}=s_{0} \cdot\left(\prod_{i=1}^{N} k_{i}^{(3)}-\prod_{i=1}^{N} k_{i}^{(1)}\right),
\end{aligned}
$$

where $\Delta s^{\text {ideal }}$ are $\Delta s^{\text {real }}$ are the efficiency of the ideal and real information system, respectively;

$S_{0}$ is the initial value of performance indicator;

$k_{i}^{(1)}, k_{i}^{(2)}, k_{i}^{(3)}$ are the values of the coefficient of dynamics of the first, second and third kind, respectively, at the $i$-th stage of the process;

$N$ is the number of stages of the process.

The given reasoning can be extended with the case when not one but several per- 
formance indicators are considered for the process. In this case instead of a vector of indicator values we will have a matrix $\mathrm{S}=\left\{s_{i j}\right\}, i=\overline{0, N}, j=\overline{1, M}$, where $s_{0 j}$ is the initial value of the $\mathrm{j}$-th indicator, $s_{i j}$ is the value of the $j$-th indicator after the $i$-th stage of the process, $M$ is the number of indicators, $N$ is the number of process stages.

The values of the coefficients of dynamics will be determined separately for each of the performance indicators and will also represent a matrix. For example, the values of the basic dynamics coefficients will correspond to the matrix $\mathbf{K}=\left\{k_{i j}\right\}, i=\overline{1, N}, j=\overline{1, M}$, where $s_{i j}$ is value of the $j$-th coefficient at the $i$-th stage of the process, $M$ is the number of indicators, $N$ is the number of stages of the process. For the coefficient of dynamics of the first, second and third kind there will be similar matrixes.

\section{Conclusion}

Increasing the efficiency of company activities can be achieved by implementing informa- tion systems, which is associated with appropriate changes in the organizational structure and organization of business processes. However, the risks associated with these actions cause us to think about the feasibility of the project. At the same time, problems from the production and management activities prior to the introduction of an information system also represent a certain threat to the company. Thus, it is possible to assess the IT project by taking into account both positive and negative consequences of the implementation of the system.

\section{Acknowledgments}

This work was funded by Ministry of Science and Higher Education of the Russian Federation (State assignment "Structure and properties of the polymer materials produced using a system of chemically, thermally and / or mechanically induced both surface and bulk modification techniques," topic number FZRR-2020-0024, code 0699-20200024).

\section{References}

1. Khanfar A.A., Mavi R.K., Jie F. (2018) Prioritizing critical failure factors of IT projects with fuzzy analytic hierarchy process. Proceedings of the International Conference on Mathematics, Engineering and Industrial Applications (ICoMEIA), Kuala Lumpur, Malaysia, 24-26 July 2018, vol. 2013, no 020058. DOI: $10.1063 / 1.5054257$.

2. Sorooshian S., Mun S.Y. (2020) Literature review: Critical risk factors affecting information-technology projects. Quality - Access to Success, vol. 21, no 175, pp. 157-161.

3. Isaev E.A., Samodurov V.A., Pervukhin D.V., Filyugina E.K. (2019) The application of convolutional neural networks $(\mathrm{CNN})$ to search for patterns of various nature in data series. Industrial Automatic Control Systems and Controllers, no 12, pp. 24-32 (in Russian). DOI: 10.25791/asu.12.2019.1069.

4. Pervukhin D.V., Isaev E.A., Rytikov G.O., Filyugina E.K., Hayrapetyan D.A. (2019) Analysis of the positive effect of the IT solutions implementation based on risk assessment. Instruments and Systems: Monitoring, Control, and Diagnostics, no 7, pp. 45-54 (in Russian). DOI: 10.25791/pribor.07.2019.742.

5. Ayuso S., Rodriguez M.A., Garcia-Castro R., Arino M.A. (2014) Maximizing stakeholders' interests: An empirical analysis of the stakeholder approach to corporate governance. Business \& Society, vol. 53, no 3, pp. 414-439. DOI: 10.1177/0007650311433122.

6. Mishra A., Sinha K.K., Thirumalai S, Van de Ven A. (2020) Sourcing structures and the execution efficiency of information technology projects: A comparative evaluation using stochastic frontier analysis. Journal of Operations Management, vol. 66, no 3, pp. 281-309. DOI: 10.1002/joom.1064. 
7. Klaus-Rosinska A. (2017) Concept of measuring the performance of IT projects. Proceedings of the 25th International Conference on Systems Engineering (ICSEng), Las Vegas, US, 22-24 August 2017, pp. 412-417. DOI: 10.1109/ICSEng.2017.63.

8. Rodriguez A., Ortega D., Concepcion R. (2017) An intuitionistic method for the selection of a risk management approach to information technology projects. Information Sciences, vol. 375, pp. 202-218. DOI: 10.1016/j.ins.2016.09.053.

9. Shafiee S., Kristjansdottir K., Hvam L., Forz C. (2018) How to scope configuration projects and manage the knowledge they require. Journal of Knowledge Management, vol. 22, no 5, pp. 982-1014. DOI: 10.1108/JKM-01-2017-0017.

10. Pervukhin D.V., Isaev E.A., Rytikov G.O., Filyugina E.K., Hayrapetyan D.A. (2020) Theoretical comparative analysis of cascading, iterative, and hybrid approaches to IT project life cycle management. Business Informatics, vol. 14, no 1, pp. 32-40. DOI: 10.17323/2587-814X.2020.1.32.40.

11. Boehm B.W. (1991) Software risk management: Principles and practices. IEEE Software, vol. 8, no 1, pp. 32-41. DOI: 10.1109/52.62930.

12. Gregory P.H. (2010) CISA certified information systems auditor all-in-one exam guide. New York: McGraw-Hill.

13. Ako-Nai A., Singh A.M. (2019) Information technology governance framework for improving organizational performance. South African Journal of Information Management, vol. 21, no 1, article no a1010. DOI: 10.4102/sajim.v21i1.1010.

14. U1 Haq S., Gu D., Liang C., Abdullah I. (2019) Project governance mechanisms and the performance of software development projects: Moderating role of requirements risk. International Journal of Project Management, vol. 37, no 4, pp. 533-548. DOI: 10.1016/j.ijproman.2019.02.008.

15. Almutairi M., Riddle S. (2018) A framework for managing security risks of outsourced IT projects: An empirical study. Proceedings of the International Conference on Software Engineering and Information Management (ICSIM 2018), Casablanca, Morocco, 4-6 January 2018, pp. 40-44. DOI: $10.1145 / 3178461.3178476$.

16. Bokolo A. (Jr.), Pa N.C., Nor R.N.H., Jusoh Y.Y., Aris T.N.M. (2018) Implementation of risk mitigation among IT governance practitioners in Malaysia. Advanced Science Letters, vol. 24, no 2, pp. 1344-1347. DOI: $10.1166 /$ asl.2018.10746.

17. Lee J.S., Keil M., Shalev E. (2019) Seeing the trees or the forest? The effect of IT project managers' mental construal on IT project risk management activities. Information System Research, vol. 30, no 3, pp. 1051-1072. DOI: 10.1287/isre.2019.0853.

18. Lai S.-T., Leu F.-Y. (2017) A critical quality measurement model for managing and controlling big data project risks. Proceedings of the 12th IEEE International Conference on Broadband Wireless Computing, Communication and Applications (BWCCA), Barcelona, Spain, 8-10 November 2017, vol. 12, pp. 777-787. DOI: 10.1007/978-3-319-69811-3_69.

19. Pike G. (2006) Supporting business innovation while reducing technology risk. White paper. Walldorf, Germany: SAP AG.

20. Wu D.J., Ding M., Hitt L.M. (2013) IT implementation contract design: Analytical and experimental investigation of IT value, learning, and contract structure. Information Systems Research, vol. 24, no 3, pp. 787-801. DOI: 10.1287 isre.1120.0448.

21. Ghribi S., Hudon P.A., Mazouz B. (2019) Risk factors in IT public-private partnership projects. Public Works Management \& Policy, vol. 24, no 4, pp. 321-343. DOI: 10.1177/1087724X18823009.

22. Didraga O., Brandas C., Batagan L., Alecu F. (2019) Characteristics of effective IT project risk management in Romanian IT companies. Economic Computation and Economic Cybernetics Studies and Research, vol. 53, no 4, pp. 176-193. DOI: 10.24818/18423264/53.4.19.11. 
23. Pimchangthong D., Boonjing V. (2017) Effects of risk management practices on IT project success. Management and Production Engineering Review, vol. 8, no 1, pp. 30-37.

DOI: 10.1515/mper-2017-0004.

24. Neumeier A., Radszuwill S., Garizy T.Z. (2018) Modeling project criticality in IT project portfolios. International Journal of Project Management, vol. 36, no 6, pp. 833-844.

DOI: 10.1016/j.ijproman.2018.04.005.

25. Maruping L.M., Venkatesh V., Thong J.Y.L., Zhang X. (2019) A risk mitigation framework for information technology projects: A cultural contingency perspective. Journal of Management Information Systems, vol. 36, no 1, pp. 120-157. DOI: 10.1080/07421222.2018.1550555.

26. Lee J.S., Keil M. (2018) The effects of relative and criticism-based performance appraisals on task-level escalation in an IT project: a laboratory experiment. European Journal of Information Systems, vol. 27, no 5, pp. 551-569. DOI: 10.1080/0960085X.2017.1408752.

27. Gloria I. (Jr.), Chaves M.S. (2017) Identification and mitigation of risks in IT projects: a case study during the merger period in the telecommunications industry. Revista de Gestao e Projetos, vol. 8, no 3, pp. 1-17. DOI: $10.5585 /$ gep.v8i3.581.

28. ISACA (2012) COBIT5. A business framework for the governance and management of enterprise IT. ISACA.

29. Almutairi M., Riddle S. (2018) Managing outsourced IT projects' security risks: A case study. Proceedings of the 10th International Conference on Information Management and Engineering (ICIME 2018), Manchester, England, 22-24 September 2018, pp. 21-26. DOI: 10.1145/3285957.3285986.

30. Thirasakthana M., Kiattisin S. (2018) Identifying standard testing time for estimation improvement in IT project management. Proceedings of the 3rd Technology Innovation Management and Engineering Science International Conference (TIMES-iCON), Bangkok, Thailand, 12-14 December 2018, pp. 1-5. DOI: 10.1109/TIMES-iCON.2018.8621787.

\section{About the authors}

\section{Eugeni A. Isaev}

Cand. Sci. (Tech.);

Senior Researcher, Institute of Mathematical Problems of Biology, Russian Academy of Sciences (Branch of the Keldysh Institute of Applied Mathematics, Russian Academy of Sciences), 1, Professor Vitkevich Street, Pushino, Moscow Region 142290, Russia;

E-mail: is@itaec.ru

ORCID: 0000-0002-3703-447X

\section{Dmitry V. Pervukhin}

Senior Lecturer, State University of Management, 99, Ryazansky Prospect, Moscow 109542, Russia;

E-mail: dvperv@gmail.com

ORCID: 0000-0001-6500-035X

\section{Georgy O. Rytikov}

Cand. Sci. (Phys.-Math.);

Associate Professor, State University of Management, 99, Ryazansky Prospect, Moscow 109542, Russia; Associate Professor, Moscow Polytechnic University, 38, Bolshaya Semyonovskaya Street, Moscow 107023, Russia;

E-mail: GR-yandex@yandex.ru

ORCID: 0000-0001-5521-8662 


\section{Ekaterina K. Filyugina}

Impact Electronics Ltd., 14/19 build. 8, Novoslobodskaya Street, Moscow 127055, Russia;

E-mail: ekaterina.filyugina@mail.ru

ORCID: 0000-0001-6461-7235

\section{Diana A. Hayrapetyan}

Economist, Epokha Vozrozdeniya Ltd., 13 build. 2, Rusakovskaya Street, Moscow 107078, Russia;

E-mail: hayrapetyandiana@gmail.com

ORCID: 0000-0001-6646-1748 